\title{
The Construction and Operation of "Five-Oriented" Cultivation Model for Innovative and Entrepreneurial Quality of College Students*
}

\author{
WANG Lian-sen, LI Ying, SUN Hong-feng, WANG Lu \\ Shandong Women's University (SWU), Jinan, China
}

\begin{abstract}
Since 2010, Shandong Women's University, as the third undergraduate colleges for female in China and first in Shandong Province, incumbently undertook the mission of exploring unique law for innovative and entrepreneurial education of female college students, constructed and implemented "five-oriented" cultivation modes for innovative and entrepreneurial quality of female college students based on the theories of Quality Education Theory, Entrepreneurial Ecology Theory, Educational Engineering Theory, Gender Differences Theory, and Differentiated Teaching Theory. The first is "Generalization-Oriented" Cultivation Objective, having established the innovative and entrepreneurial goals for female college students in six dimensions including consciousness, thinking, spirit, knowledge, ability, and personality. The second is "Integralization-Oriented" Cultivation Channel, having founded and intensified the collaboration and linkage among channels like first classroom, second classroom, and platform on and off campus. The third is "Collaboration-Oriented" Cultivation Measures, having founded and intensified the matching and coordination among system, mechanism, teachers, resource, and other measures. The fourth is "Circulation-Oriented" Cultivation Process, arranging and intensifying steps like investigation and research, design and plan, action and supervision, and concluding and evaluation orderly operating, forming closed-circuit and advance in circulation. The fifth is "Differentiation-Oriented" Cultivation Methods. This mode has efficiently solved the problems, like unclear purpose, unknown direction, incomplete distribution and scattered forces, insufficient conditions and inefficient measures, poor arrangement and flow, neglecting differences and not fine enough, existing in the innovative and entrepreneurial education for female college students, which made their innovative and entrepreneurial qualities greatly promoted and enthusiasm and efficiency to participate in the innovative and entrepreneurial activities enhanced.
\end{abstract}

Keywords: entrepreneurial education, entrepreneurial quality, innovative quality, Shandong Women's University (SWU), five-oriented

\footnotetext{
* Acknowledgement: This research was financially supported by Humanities and Social Science Research Project of Ministry of Education (Grant No. 15YJA880069), Research Project to Talent Introduced of Shandong Women's University (No. 2016RCYJ16), Preschool Teacher Education Talent Team-Advantage Disciplines Cultivation Plan of Shandong Provincial Higher Education Institutions, Research Project of Teaching Reform of Shandong Women's University (SWU) (2017).

WANG Lian-sen, professor, member of Preschool Teacher Education Talent Team-Advantage Disciplines Cultivation Plan of Shandong Provincial Higher Education Institutions, School of Education, Shandong Women's University (SWU).

LI Ying, professor, Office of Academic Research, School of Data Science and Computer, Shandong Women's University (SWU).

SUN Hong-feng, professor, School of Data Science and Computer, Shandong Women's University (SWU).

WANG Lu, associate professor, Youth League Committee, Shandong Women's University (SWU).
} 
The innovation and entrepreneurship education for college students has been operated for many years and has achieved remarkable results, but there are still some problems, which need to be reformed and innovated according to relevant theories. In this regard, especially for female college students, Shandong Women's University (SWU) has made a good attempt.

\section{Main Problems in Innovative and Entrepreneurial Education}

\section{Unclear Purpose and Unknown Directions on Innovative and Entrepreneurial Education}

Fail to focus on and carry out in detail the cultivation of innovative and entrepreneurial quality, simplified the definition of quality, restricted to the aspects of innovative and entrepreneurial knowledge and skill, while neglecting the dimensions of consciousness, thinking, spirit, and personality to make innovative and entrepreneurial education formalistic and superficial.

\section{Incomplete Distribution and Scattered Forces on Innovative and Entrepreneurial Education}

Fail to fully mobilize and promote all the departments and staff to pay close attention to study and implement innovative and entrepreneurial education together, fail to integrate the available educational channels and achieve the effect of " $1+1>2$ ", divided policies from various sources, each department acting on its own, overlapping leadership.

\section{Insufficient Conditions and Inefficient Measures on Innovative and Entrepreneurial Education}

Inadequate teachers and their level, less investment in resources, incomplete and inappropriate setting and arrangement of system and mechanism, failure to arouse the enthusiasm of teachers, students, and all the departments, lower compatibility and coordination among measures.

\section{Poor Arrangement and Flow of Innovative and Entrepreneurial Education}

Fail to make long-term arrangement and scientific design for innovative and entrepreneurial education, keen on "short, adaptable, and fast", sometimes "hot" and sometimes "cold", now tense and now relaxed, poor consistency and systematicness.

\section{Neglecting Differences and not Fine Enough of Innovative and Entrepreneurial Education}

Inadequately emphasize the subject status of students, neglecting their differences among gender, grades, majors, and personality, weak awareness and not enough degree of "differentiation" education and teaching, used to adopt the educational channels, measures, manner, and methods of uniformity to make the innovative and entrepreneurial education less targeted, insufficient efficiency, and stay the extensive stage.

\section{Theoretical Bases to Solve Problems}

\section{Quality Education Theory}

The ultimate goal of innovative and entrepreneurial education is to cultivate the comprehensively innovative and entrepreneurial quality.

Quality is the subjective qualities of a person, developed and formed through educational and social practice activities based on the native endowment, namely the systematic integration of the morality, intelligence, physical strength, aesthetic qualities of him/her and their expressive abilities, and the essential basis and condition for a person to do one job. 
Quality education is a kind of education, which takes paying much attention to the development of educatees' potentials and promoting the brisk and active development of educatees' morality, intelligence, body, and other aspects as the basic features. Quality education is the ultimate goal of school education. "Innovative education aims to foster the creative quality of students" (Xin \& Lin, 2006, p. 8).

The purpose of innovative and entrepreneurial education implemented by colleges and universities for college students does not lie in the education activities (means) themselves, but in its result-eventual formation of educates' innovative and entrepreneurial quality. The quality of innovative and entrepreneurial eventually needs to be tested via the innovative and entrepreneurial quality. The constitution of innovative and entrepreneurial quality possesses the comprehensive characteristic of multi-dimensions and multi-components (Zhou, 2002; Liu, 2006; Wang, 2017). According to the Guilford's construct system on creation (Guilfordj, 1967), innovative and entrepreneurial quality of college students can be divided into six dimensions of innovative and entrepreneurial awareness, innovative and entrepreneurial thinking, innovative and entrepreneurial spirit, innovative and entrepreneurial knowledge, innovative and entrepreneurial ability, innovative and entrepreneurial personality, and each dimension includes various components (indexes), 37 all together (Li, 2016) (as shown in Figure 1).

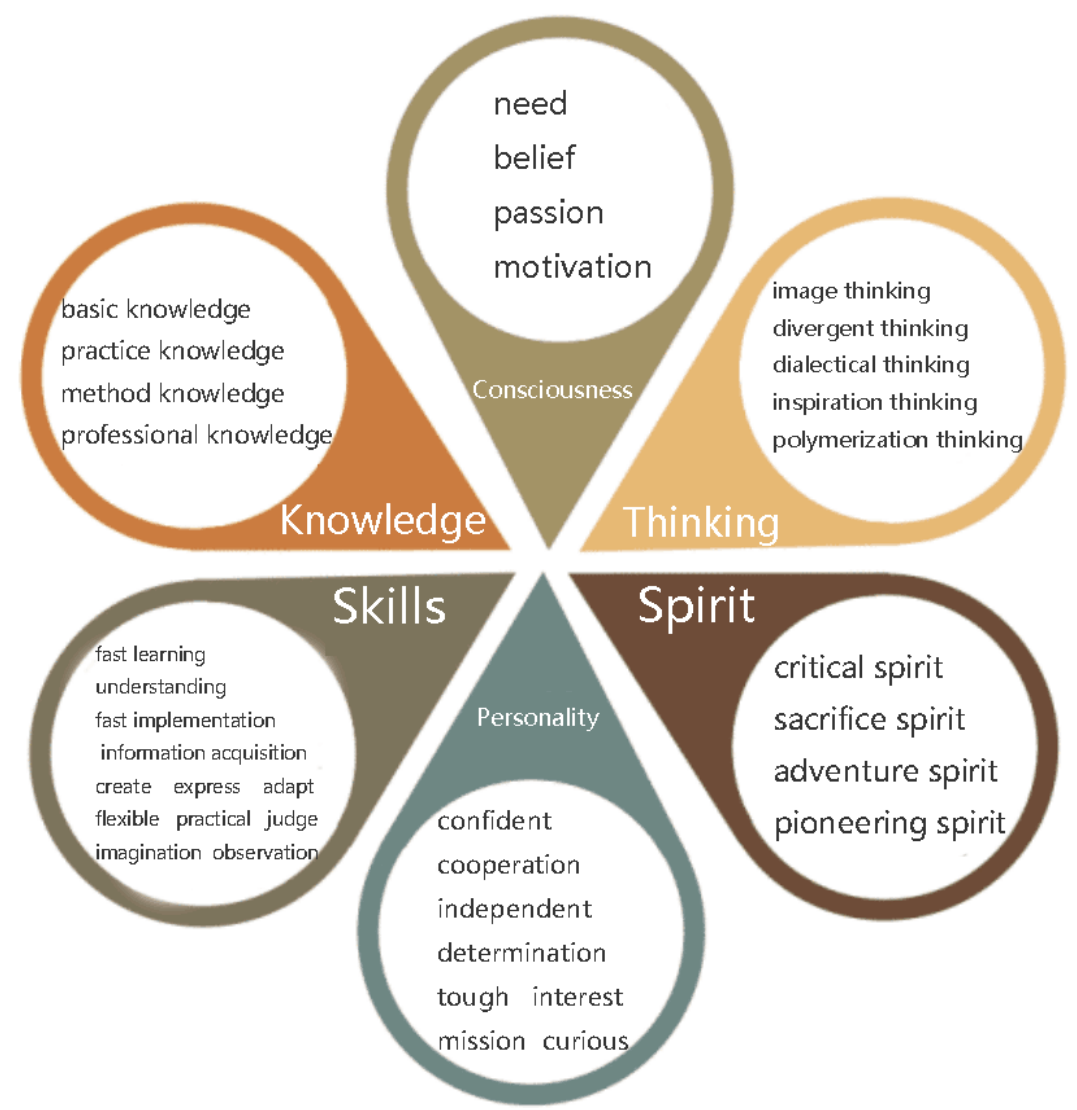

Figure 1. The constitute of innovative and entrepreneurial quality of college students.

\section{Entrepreneurial Ecology Theory}

The cultivation of innovative and entrepreneurial quality must be in virtue of synthetic force of mass' multi acting force points. 
Colleges implement innovative and entrepreneurial education, and cultivating college students' multi-component, multi-dimensional comprehensive innovation, and entrepreneurial quality need to create a integrated, excellent, and dynamic "entrepreneurial ecology system"; to dig and make some acting force points focusing on six dimensions of innovative and entrepreneurial quality (as shows in Table 1); and to make use of its comprehensive efficiency.

Table 1

Cultivating Acting Force Points (Channels) of Innovative and Entrepreneurial Qualities

\begin{tabular}{|l|l|}
\hline First-degree factors & Second-degree factors \\
\hline First classroom & $\begin{array}{l}\text { Curriculum System, Practical Educational System, Quality Expansion System, and Quality } \\
\text { Supervision and Assurance System }\end{array}$ \\
\hline Second classroom & $\begin{array}{l}\text { Academic Contest, Social Practice, Association Activities, Academic Activities, and Cultural } \\
\text { Activities }\end{array}$ \\
\hline Platform on campus & Experimental Center, Practical Training Base, Practice Base, and Incubation Base \\
\hline Platform off campus & Practical Training Base, Practice Base, Internship Base, and Incubation Base \\
\hline
\end{tabular}

\section{Educational Engineering Theory}

Innovative and entrepreneurial education for college students as a system engineering must be in virtue of many measures like system, mechanism, teachers, and resources to be realized.

"Educational engineering" was initially put forward by Yu Guang-yuan at National Education Science Planning Conference in the spring of 1978. Educational engineering is faced with the concrete educational practice, and addresses the real practice issues in educational activities, and its core is the engineering system of analysis, design, implementation, and test.

Educational engineering taking "why" and "how" as basis and premise, and considering various variable parameters and environment constraints in educational practice, puts forward practicable countermeasure plans and applies them into "how" actions and initiatives. The implementing of educational engineering has to resort to the guidance of Information Theory/Cybernetic Theory/System Theory. Innovative and entrepreneurial education for college students, as a systematic project, will only be realized by working out various steps of analysis, design, implementation, test and various measures of system, mechanism, teachers, and resources under the guidance of scientific theories (as shown in Table 2).

Table 2

Cultivating Measures for Innovative and Entrepreneurial Qualities

\begin{tabular}{|l|l|}
\hline First-degree factors & Second-degree factors \\
\hline System & Plan, Lead, Organize, Manage, Control, and Supervise \\
\hline Mechanism & $\begin{array}{l}\text { Institutional Mechanism, Cultural Mechanism, Public Opinion Mechanism, Evaluational } \\
\text { Mechanism, Incentive Mechanism, and Research Mechanism }\end{array}$ \\
\hline Teachers & Idea, Attitude, Spirit, Knowledge, Skill, and Quality \\
\hline Resources & Financial Resources, Material Resources, Policy Resources, and Social Resources \\
\hline
\end{tabular}

\section{Gender Differences Theory}

Male and female college students have differences in many aspects like innovative and entrepreneurial qualities and their influential factors.

Gender difference theory accepts that "males and females should be treated differently". Generally speaking, in personality, male is brave and generous, resolute with strong desire on success and independence, 
but inclined to be opinionated; female is tender, delicate, exquisite, virtuous, and kind, but tends to be of indecision and conservation (Liu, 2015). Reliability and kindness of females is higher than that of male, and aggressiveness and independence of males is stronger compared with females. In intelligence, there is no significant difference between male and female, but language expression ability and artistic sensibility of females are better than that of males, while space, mathematics, and inferential abilities of males are better than that of females.

Specific to the innovative and entrepreneurial quality, the survey indicates that creative awareness, spirit, and personality of males are generally better than that of females; but females are generally superior to males in creative knowledge and thinking, and posses excellent potentials for creation and entrepreneur, like abilities of sharp intuitive judgment, active imagery thinking, outstanding language expression, superb balance and coordination, and patient endurance.

Besides, there also exist gender differences in the influencing factors for the development of innovative and entrepreneurial quality. Survey indicates that the most remarkable factors for males, in turn, are development interests, innovative platform, and teacher-student relationship, etc., and for females, teacher-student relationship, development interests, classmates relationship, and so on.

Compared with males, females tend to have more obvious response to incentives from teachers, parents, classmates, counselors, and others, but males are good at the application of innovative platform, initially participating innovative activities, and sensitive to the innovative incentives ( $\mathrm{Li}, 2016)$.

\section{Differentiated Teaching Theory}

The cultivating of innovative and entrepreneurial qualities should demonstrate the dominant position of students, care the differences, and teach students in accordance of their aptitude and gender.

Differentiated teaching refers to the teaching meeting individual needs of students to promote they fully developed on the original basis. This theory, developed on the bases of Bloom's taxonomy, Gardner's theory of multiple intelligences, and theory of optimizing classroom teaching, is akin to "teach students in accordance with their aptitude" what emphasized in the Confucius philosophy Analects of Confucius-Yong Ye, that is, education and teaching should consider individual difference of each student, and take special measures to satisfy the needs of each student in accordance with different characteristics of different students.

Implementing the innovative and entrepreneurial education on college students not only should establish the identified requirements of innovative and entrepreneurial quality (like general awareness, general thinking, general spirit, general knowledge, general ability, and general personality) in the direction, adopting identified channels and measures on the methods, but also pay much attention to the differentiation (such as gender difference, major difference, and characteristics difference) in the direction, adopting differentiation actions on the methods to carry out comprehensive cultivating of innovative and entrepreneurial quality, which is precise in the direction and nuanced on the methods based on integrating the point and sphere.

\section{"Five-Oriented" Cultivation Model From SWU}

In 2010, facing the situation that number of female students gradually increases in higher education (female college students accounts for $46 \%$ in college graduates and over $70 \%$ in normal universities and colleges) and the fact that there are marked gender differences (physiology, psychology, and society) between male and female, SWU, as the third undergraduate colleges for female in China and first in Shandong Province, 
incumbently undertook the mission of exploring unique law for innovative and entrepreneurial education of female college students, constructed and implemented "five-oriented" cultivation modes for innovative and entrepreneurial quality of female college students (as shown in Figure 2).

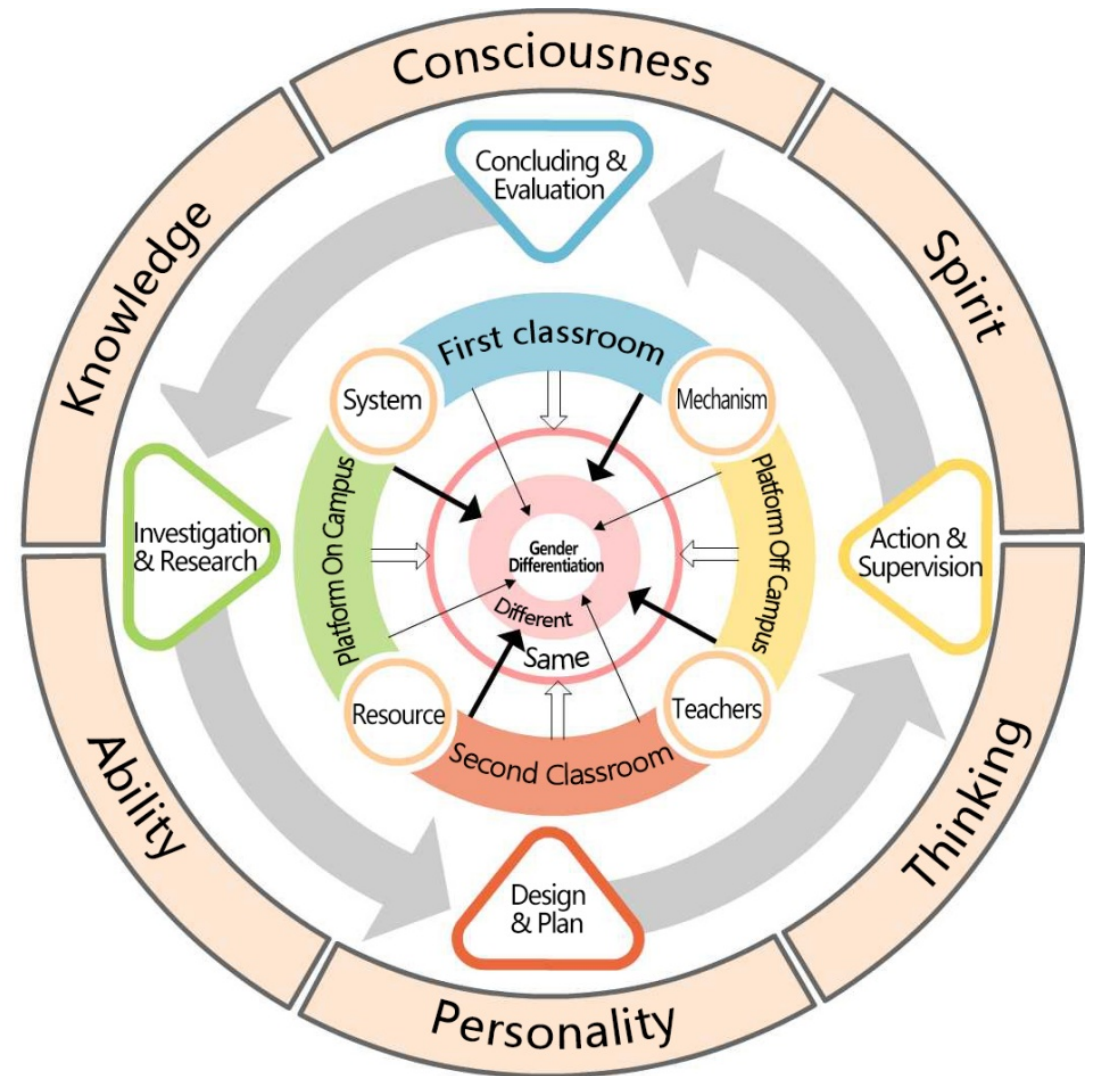

Figure 2. "Five-oriented" cultivation modes for innovative and entrepreneurial quality of female college students.

Having Comprehensively Established Innovative and Entrepreneurial Quality Objectives of Female College Students Including Consciousness, Thinking, Spirit, Knowledge, Ability, and Personality

SWU has defined the positioning of cultivating objectives of "meeting the development demands of local economy, society, women, and children, cultivating high-quality, applied, and special talents with a solid professional foundation, strong abilities for application and practice, innovative spirit, independent learning capability, social gender awareness, and all-round development of morality, intelligence physique and aesthetic", since promoted to the undergraduate college in 2010. This overall objective of talents cultivation has united the thinking and understanding of all the departments and staff in our university, and focused the objectives of innovative and entrepreneurial education on the cultivation of comprehensive innovation and entrepreneur quality including entrepreneurial awareness, thinking, spirit, knowledge, ability, and personality.

Create Channels Like First Classroom, Second Classroom, Platform on Campus, Platform off Campus, Strengthen the Coordination and Linkage, and Integratedly Cultivate the Innovative and Entrepreneurial Quality of Females

Build two platforms both on and off campus. SWU takes the objective of intensifying the cultivation of innovative spirit and ability of entrepreneurial practice of college female students, pays much attention to the gender differences, establishes start-up base for college students at east and west area covering 500 square 
meters on campus in 2011, makes a laboratory building over 10,000 square meters open for innovative and entrepreneurial projects of college students, uses for practical training and incubation of entrepreneurial projects, and turns it into a practice platform for starting up on the basis of cooperation between enterprises and university. SWU designed and founded "Circle Space" communicative center for innovation and start-up of college students in the central area on campus in 2016. In 2014, it was approved as the comprehensive quality practice training center of college students in Shandong Province. SWU together with Women Federation of Shandong Province co-founded Shandong Women's Entrepreneurial University in July 2015, as the first in China, and only women's entrepreneurial college in Shandong Province.

It established key research center for innovative and entrepreneurial education of females in Shandong Province, and was honored "provincial entrepreneurial incubation demonstration base for college students in Shandong Province" by the Department of Human Resources and Social Security and Department of Finance of Shandong Province, becoming one of the 10 provincial entrepreneurial demonstration platforms in Shandong Province in 2016. SWU is earlier awarded "Undergraduate KAB Entrepreneurship Education Base" and "Undergraduate KAB Entrepreneurship Club" by All-China Youth Federation, All-China Students' Federation, and International Labor Organization among colleges and universities in province. In March 2016, SWU signed Cooperation Framework Agreement with Lin Gang District Government, Lin Yi City, co-founded Heroine Entrepreneurship Park with him, and established Li Yi branch of SWU along with Women Federation of Lin Yi City and Lin Gang District Government, making full use of innovative leading role of Shandong Women's Entrepreneurship University and encouraging and assistanting local leftover women to participating in entrepreneur and serving the local economy and society.

SWU docking with Haier Group established Haier Maker Laboratory of Shandong Women's Entrepreneurship University in May 2016. In July 2016, SWU as well as Shandong Xilian Power Electronic Commerce Co. Ltd., co-founded undergraduate employment and entrepreneurship bases, establishing e-commerce start-up incubation base for females in Tianhua Industrial Park of Heze City, household start-up incubation base for females in Yimeng Senior Sister start-up service center of Linyi City, and cultural creativity incubation base for females in CCPARK creativity port of Jinan City. SWU docking with Shandong Dura Information Technology Co. Ltd., established employment and entrepreneurship cooperative units of SWU in November 2016. It actively cooperates with enterprises, and deeply discusses the reform of talents cultivating mode, teaching contents, teaching methods, and evaluation methods. SWU cooperating with enterprises like Inspur Group, Beijing Huike, and Shandong New Vision has established seven school-enterprise cooperation majors and six laboratories, deeply explored collaborative education mechanism and fusion mechanism of production and teaching, and effectively improved undergraduate professional capacity and innovative and entrepreneurial quality.

Link the first classroom and second classroom. SWU has constructed the innovative and entrepreneurial quality cultivation system constituted by "Liberal Education + Professional Education + Innovative and Entrepreneurial Education + Innovative and Entrepreneurial Practice", having integrated innovative and entrepreneurial concept and content into each procedure, like classroom teaching, practice system, and teaching evaluation throughout the whole process of talents cultivation, having developed professional courses displaying the industrial characteristics and involved in innovative and entrepreneurial thinking and methods; elective and compulsory courses of liberal education in innovative and entrepreneurial quality listed "Femaleology Introductory Theory" like courses as compulsory, added innovative and 
entrepreneurial scores to encourage undergraduate to participate in various academic contests and innovative and entrepreneurial competition, such as mathematical modeling, Internet + , publishing papers, and applying patents and programs. So far, SWU has opened up to 28 liberal courses of innovation and entrepreneurship for undergraduate, and published nine series of textbooks of comprehensive innovative and entrepreneurial qualities for female undergraduate, like Women and Science, Women and Law, Women and Financing, Women and Marriage, etc.

SWU adheres to the innovative and entrepreneurial education thinking of "Autonomy is the key, personality is base point, interest is motivation, and project is the carrier", extensively develops the innovative and entrepreneurial second classroom activities in various forms, like studying and discussing, and involvement of all people to achieve the organic unity of brain training (innovative thinking), hands training (manual dexterity), mouth training (communication and expression), mind training (creative awareness) of undergraduate, and focus on nurturing students' innovative and entrepreneurial qualities.

SWU has established public service platform for innovative and entrepreneurial information and carried out the instructive and serving work on innovation and entrepreneurship though making full use of media like Network, MicroBlog, Wechat, mobile phone clients, etc. SWU has developed "Youth Women's University" and "Scholarly Women's University" activities to cultivate and promote spiritual ethos and cultural quality for female undergraduate; organized "Women Entrepreneurship Forum" and "Entrepreneurial Auditorium for Qi Lu Women", in which the entrepreneurial educational experts, typical entrepreneurs, and women entrepreneurs are invited to tell their entrepreneurial experiences and instruct undergraduates to implement entrepreneurial activities; held the "Qingzhao Auditorium" whose main content is "Talking Women, Women Talking" to intensify the innovative thinking and awareness of female undergraduate; hosted various entrepreneurial training programs, like e-commerce Entrepreneurial Training Camp of Shandong Women's Entrepreneurship University, Undergraduate Entrepreneurship Special Training Camp, Undergraduate "Pilot Entrepreneurship Training", and "Tea Creating Life".

\section{Perfect the Measures Including Systems, Mechanism, Teachers, Resources, Intensify Their Compatibility and Coordination, and Collaboratively Cultivate the Innovative and Entrepreneurial Qualities of Female Undergraduate}

Optimize two securities of system and mechanism. SWU has formed innovative and entrepreneurial education work steering group, undergraduate entrepreneurial education steering committee, undergraduate innovative and entrepreneurial incubation base management committee, established special funds for undergraduate innovative and entrepreneurial incubation, made and implemented dozens of related regulations, such as "The Procedures on the Management of Undergraduate Entrepreneurial Base", "Innovative and Entrepreneurial Education Reform Implementation", "Regulations for Undergraduate Innovation Scores", and "The Procedures on the Affirmation and Management of Undergraduate Innovative and Entrepreneurial Practice Scores", adopting the joint instructions of teachers and enterprise experts, on the basis of engineering practice projects, and undergraduate scientific innovation activities, like academic contests, papers, and programs as the carrier, cultivated the innovative and entrepreneurial abilities of undergraduate, and offered an excellent platform for the cultivation of high quality innovative and entrepreneurial talents.

Lay two grounds of teachers and resources. SWU has built experienced professional and part-time teachers team both on and off campus. It is required to at least cultivate one teacher of each major specialized 
in innovative and entrepreneurial education, and arrange professional teachers to do post practice in the enterprises as planned. SWU has hired innovative and entrepreneurial successors and enterprisers to be the part-time instructor for innovation and entrepreneurship, and built the mechanism that teachers in university take a temporary post in enterprises, asking all the full-time and part time entrepreneurial tutors in university to have at least one year experience of industrial and enterprise working or entrepreneurship.

SWU encourages teachers to give instructions on students' innovative activities and project, attracting students to participate in their projects. SWU also guides tutors to actively engage in the innovative and entrepreneurial education, integrating it into the professional curriculum teaching. Innovative and entrepreneurial training courses for teachers are created by sending or inviting innovative and entrepreneurial education experts, and the promotion of teachers' innovative and entrepreneurial awareness and abilities is gradually put as important contents of pre-job training, curriculum training in rotation and backbone training. SWU refined the qualifications of teacher recruiting position, and made experience of industrial enterprise working or part-time working as the primary conditions for recruiting related professional teachers and entrepreneurial tutors. The performance of innovative and entrepreneurial education has been brought into teachers' professional and technical posts and performance appraisal. As to teachers with outstanding achievements, SWU offers separate policies, indexes, and expenditure, and gives major incentive and support.

Arrange Investigation \& Research, Design \& Plan, Action \& Supervision, and Concluding \& Evaluation and Other Processes, Intensify Them to Operate Orderly, Smoothly, Spirally, "Cyclically" Cultivate the Innovative and Entrepreneurial Quality of Female College Students

The "five-oriented" cultivation modes for innovative and entrepreneurial quality of female college students is a promoted project in cycle; each cycle is one year, and has been carried out for four cycles. Each cycle includes four phases as follows:

First phase: concluding \& evaluation (in the end of the second semester in each school year). Project Team summarizes innovation and entrepreneur educational work of all departments (Office of Academic Affairs, SWU Communist Youth League of China, Office of Enrollment and Employment, and Office of Students Affairs) and schools/colleges in SWU, and evaluates the achievements and shortcoming in the innovative and entrepreneurial cultivation for female undergraduates.

Second phase: investigation \& research (in the end of the second semester in each school year, summer holiday). Considering the situation of summarization and evaluation, coming into the departments and schools/colleges, facing up to managerial personnel, teachers, and students, Project Team makes further investigation of key issues, collects and analyzes the thinking and practices of other colleges and universities, and deepens and enriches the theoretical construction of five-oriented cultivating model of innovative and entrepreneurial qualities for female undergraduate.

Third phase: design \& plan (summer holiday). Project Team should make a complete and thorough design for innovative and entrepreneurial education work in the next school year on the basis of concluding and evaluation, investigation, and research, make feasible planning on teachers, resources, system, and mechanism, and submit to university (SWU) for examination and approval.

Fourth phase: action \& supervision (the first and second semesters of next school year). University (SWU) should plan and arrange the innovative and entrepreneurial education work of next school year, in 
accordance to design and planning advice which has been passed through the examination, and organize the specially assigned persons to supervise work regularly or irregularly.

After finishing all the four phases above, a new cycle (concluding \& evaluation, investigation $\&$ research, design \& plan, and action \& supervision) will be started, moving in circles, cycle-forwarding, and spirally rising.

Pay More Attention to Biological Gender, Psychological Gender, and Social Gender, Teach Students in Accordance of Their Gender, and Differently Cultivate Innovative and Entrepreneurship Qualities of Female College Students

Considering female generally with gender advantages (like excellent imaginary thinking, strong communicative ability, exquisite, patient, gentle, and steadfast), and gender disadvantages (like weak independence, poor pioneering, and indecision), in the construction of the first classroom, second classroom, and establishment of platforms on and off campus, the university (SWU) pays much attention to adopting their good points and avoiding their shortcomings, teaching students in accordance of their gender, fully digging their potentials, highlighting their strengths, and improving their drawbacks. SWU has established some platforms on and off campus, such as Shandong Women's Entrepreneurial University, Key Research Center for Innovative and Entrepreneurial Education of Females in Shandong Province, E-commerce Start-up Incubation Base for Females in Tianhua Industrial Park of Heze City, Household Start-up Incubation Base for Females in Yimeng Senior Sister Start-up Service Center of Linyi City, and Cultural Creativity Incubation Base for Females in CCPARK Creativity Port of Jinan City, regularly hosts Women Entrepreneurship Forum, Entrepreneurial Auditorium for Qilu Women and Qingzhao Auditorium to invite women entrepreneurs to tell their entrepreneurial experiences.

SWU has published nine series of textbooks of innovative and entrepreneurial comprehensive qualities for female undergraduate, like Women and Science, Women and Law, Women and Financing, Women and Marriage, etc., opened Femaleolgy Introductory Theory as a compulsory liberal course, hosted various entrepreneurial training programs, like E-commerce Entrepreneurial Training Camp of Shandong Women's Entrepreneurial University and "Tea Creating Life"; founded Women's Studies Institute to hold academic conferences with the themes like Women's Survival and Development and Female in the New Era, etc.; having constructed "Jinguo Plaza", "Haoyuan Plaza", and the unique sculpture, named the roads with names of successful women, creating the advanced gender culture, promoting the cultural atmosphere of self-reliance, innovation, and entrepreneurship; hosted the "Special Recruitment of Female Graduates in Shandong Province and Women Entrepreneurship Program Promotion Meeting" and "Construction and Development Forum of Shandong Women's Entrepreneurial University", increasing the innovative and entrepreneurial enthusiasm of female undergraduate and offering convenience to them. Enhancing the study on higher education of female, SWU has finished five research programs entrusted by National Women Federation and Provincial Women Federation, 10 provincial research programs, and a set of research achievements has been awarded the prize of "Chinese Women Studies Outstanding Achievements".

\section{Application and Promotion of "Five-Oriented" Cultivation Model}

Innovative and entrepreneurial qualities had been promoted constantly since this mode ("Generalization-Oriented" Cultivation Objective-“Integralization-Oriented" Cultivation 
Channel-"Collaboration-Oriented" Cultivation Measures-"Circulation-Oriented" Cultivation Process-“Differentiation-Oriented" Cultivation Methods) operated.

Innovative and entrepreneurial qualities cultivation has forced scientific and innovative achievements of higher level. Undergraduates of SWU has gained 372 provincial and national projects awards, like Mathematics Modeling, "Internet+", National Undergraduate E-commerce Challenge of "Innovation, Creativity, and Entrepreneurship", applied 78 national undergraduate innovative and entrepreneurial training planning projects, 59 patents, and published 532 papers, and applied 35 undergraduate projects in Shandong Province since 2014. Projects, patents, papers, etc., have achieved a zero breakthrough, and national grade awards also have been promoted greatly.

The successful business incubation rate for female college students is greatly promoted. Entrepreneurial entity owned by college students, which has acquired business registration, has been up to 45 by the end of 2017 and its number increases greatly compared with two to three registrations per past year.

Innovative and entrepreneurial qualities drive the higher quality employment of undergraduate. Its comprehensive employment rates of SWU have been averagely up to $97 \%$ in the last four years, and it won the title of "Provincial Employment of Undergraduate Work Advanced Group" awarded by Shandong Province Government.

Innovative and entrepreneurial education gains the social acceptance. China Education Newspaper gave a special report titled Female Entrepreneurship: Only meditation can make better tea on SWU's work in the field of innovation and entrepreneurship. Qilv.com reported the special recruitment of female graduates in Shandong Province and women entrepreneurship program promotion meeting hosted by SWU. China Entrepreneurship Education Net fully reported the university leader's experience sharing of innovative and entrepreneurial education. Xinhua Net reported the news that SWU brought innovative and entrepreneurial education into curriculum system.

Having received the financial supports from both government and society, undergraduate entrepreneurship base of SWU was rated as Provincial Undergraduate Entrepreneurial Incubation Demonstration Base by the Department of Human Resources and Society Security and Department of Finance, gaining the award and benefits capital of three million in 2016, and chosen as Spring City Jinan We Work Support Program in 2017.

The mode of innovative and entrepreneurial qualities cultivation ("Generalization-Oriented" Cultivation Objective-“Integralization-Oriented" Cultivation Channel_-"Collaboration-Oriented" Cultivation Measures - "Circulation-Oriented" Cultivation Process_- "Differentiation-Oriented" Cultivation Methods) can provide reference and learning for colleges and universities in developing innovative and entrepreneurial education, especially philosophy and practices on attention to differentiated cultivation of innovation and start-up qualities for females could been pretty ideally used to as the reference and learning for the innovative and entrepreneurial qualities cultivating of female undergraduate.

\section{References}

Guilfordj, J. P. (1967). The nature of human intelligence. New York: McGraw-Hill.

Li, Y. (2016). The development of college students' innovative and entrepreneurial quality under the gender perspective. In Shandong social science research (pp. 1-7). Jinan: Shandong People's Publishing House. (In Chinese)

Liu, J. (2015). Construction of entrepreneurship related education training system for female college students from the perspective of gender differences. Journal of Shandong Institute of Commerce and Technology, 15(3), 80-84. (In Chinese) 
Liu, S. X. (2006). Innovation quality structure analysis and its status in modern talent structure. Journal of Educational Science of Hunan Normal University, 5(3), 107. (In Chinese)

Wang, L. S. (2017). Culture construction conducive to cultivate innovative quality. In University development (pp. 215-233). New York: David Publishing Company.

Xin, Z. Q., \& Lin, C. D. (2006). Constructivist perspective of innovative quality training. Journal of the Chinese Society of Education, (5), 8. (In Chinese)

Zhou, H. (2002). On the connotation of innovative quality education and its research issue. Journal of Southwest China Normal University (Humanities and Social Sciences Edition), 28(1), 39-40. (In Chinese) 